\title{
'Fitness-for-intended-use' is an important concept in measurement
}

\author{
Paul De Bièvre
}

Published online: 15 August 2010

(C) Springer-Verlag 2010

The definition in the "International Vocabulary of Metrology-Basic and general concepts and associated uncertainties (VIM)" [1] of 'measurement result' [2] refers to a "set of quantity values being attributed to a measurand together with any other available information". Note 2 to that definition [3] adds: "A measurement result is generally expressed as a single measured quantity value and a measurement uncertainty. ..." (terms in bold mean that they refer to concepts that are themselves defined in VIM). In the VIM, "Notes" are explanatory to definitions and are considered part of them.

We discussed the "quality" of a measurement result previously [4-6]. Let us here take a special look at that most important intention we have when we carry out a measurement: the intended use of the result.

If the quality of a measurement result is guaranteed by using a 'measuring system' [7], which is calibrated by means of an appropriate 'calibrator' [8], we could all agree that that would enable to obtain an acceptable result.

Just about, but not quite.

In daily measurements performed because of specific needs, the 'measurement uncertainty' in the measurement result should be small enough for the intended use of the result. However, there is no need that it be much smaller (hence requiring unnecessarily sophisticated and expensive procedures), nor much larger (making the measurement superfluous because leading to an inappropriate result).

P. De Bièvre $(\square)$

Kasterlee, Belgium

e-mail: paul.de.bievre@skynet.be
After all, it is because of the need for some specified use of the result that a measurement is made. Hence, it is logical that it must be designed as such on beforehand. The result should be consistent with the definition of the concept measurement result, whilst at the same time, the expected measurement uncertainty should be fit-for-the-intended-use of that result. In other words, the achieved uncertainty in the result should fall within an approximate (and pre-set) 'target measurement uncertainty' [9], which is decided before the measurement.

Could it be that in a number of cases, we make too many measurements? Maybe. What more do we wish-or even need-than a measurement result falling within a pre-set target measurement uncertainty? Normally, a complete measurement uncertainty is composed of a combined Type A and Type B evaluation [10, 11]. Carrying out a 'Type A evaluation of measurement uncertainty' is easy. It is obtained from calculating a repeatability standard deviation and is usually not critical in most chemical measurement results as it is not generating the biggest component of the full final uncertainty in the result. The 'Type B evaluation of measurement uncertainty' usually constitutes the largest component of that full uncertainty and must be "evaluated" by the analyst. It is sufficient to verify that it is expected to fall within the pre-set target measurement uncertainty. If it would be expected to be much larger, there would be no need to make the measurement at all as the Type B uncertainty component is expected to be too large, rendering the result useless. "Fitness-for-intendeduse" of the measurement result is important as it prevents making too many measurements, or requiring too sophisticated measuring systems, all of which bring associated cost. On the other hand, evaluation of the Type B component of the expected uncertainty enables to ascertain whether the measurement is worth to be made at all, as the 
result could already be predicted as unsuitable before the measurement.

For years "fit-for-purpose" and "fitness-for-purpose" have been standard expressions in the (chemical) literature, but a quantification of such "fitness" was neglected or avoided altogether. In many cases, the description of specifications of the measuring instrument, or of measuring system, or of the 'measurement procedure' [12] used, were given to lead to the conclusion that a measuring system was "fit-for-purpose". That was already treated in ACQUAL previously [13]. However, without the purpose clearlyand quantitatively-specified in numbers as explained earlier, such a claim is unhelpful at best and misleading at worst.

The concept target measurement uncertainty enables an a priori decision to be made that amounts to a quantification of the required fitness-for-intended-use of the result, i.e. it constitutes a numerical value for the measurement uncertainty, which is sufficiently small as chequed against a required and pre-set aim to be attained. But also, such an approach avoids making measurements by means of measuring systems that are already recognizable as "unfit" before the measurement, thus making the measurement and their cost, useless on beforehand.

"Fitness-for-intended-use" relates a measurement result directly to the intention introduced in the definition of the 'measurand' [14] and of the target measurement uncertainty. That is helpful since the actual result has more chances to be close to what is expressed as intended measurement uncertainty. Fitness-for-intendeduse, numerically formulated as a target measurement uncertainty in any given case of measurement enables to decide already before the measurement whether the expected result would be "fit" or "unfit" for its intended use.

"Fitness-for-intended-use" is a clarifying and helpful concept associated with any measurement result.

As all metrological concepts should be ...

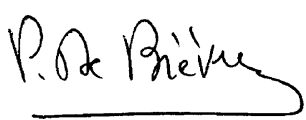

Paul De Bièvre

Editor-in-Chief

By the way, looking for justification of metrology in chemistry?

The magnitude of the copper export from Chile is about $2 \times 10^{9} \mathrm{~kg} / \mathrm{a}$. A $0.05 \%$ uncertainty in the measurement of the copper mass fraction may lead to an uncertainty in commercial value of more than USD $1 \times 10^{6}$ p.a.

[quoted by R Kaarls at the 5th Brasilian Congress of Metrology, 2009-11-09 in Salvador, Bahia, Brasil]

\section{References}

1. BIPM, IEC, IFCC, ILAC, IUPAC, IUPAP, ISO, OIML, The International Vocabulary of metrology - Basic and general concepts and associated terms (VIM), 3rd edition, JCGM 200:2008; it is usually called "VIM 3" http://www.bipm.org/en/publications/ guides/vim.html

2. BIPM, IEC, IFCC, ILAC, IUPAC, IUPAP, ISO, OIML, The International Vocabulary of metrology - Basic and general concepts and associated terms (VIM), 3rd edition, JCGM 200:2008; it is usually called "VIM 3" http://www.bipm.org/en/publications/ guides/vim.html entry 2.9

3. BIPM, IEC, IFCC, ILAC, IUPAC, IUPAP, ISO, OIML, The International Vocabulary of metrology - Basic and general concepts and associated terms (VIM), 3rd edition, JCGM 200:2008; it is usually called "VIM 3" http://www.bipm.org/en/publications/ guides/vim.html entry 2.9 , Note 2

4. De Bièvre P (2009) Manufacturing a chain logically starts with manufacturing the first link, thus is logically started a metrological traceability chain. Accred Qual Assur 14:517-519

5. De Bièvre $P$ (2009) Ensuring the potential for an intended quality of a measurement result must be done before and during the measurement, not after it (when it is too late). Accred Qual Assur $14: 351-352$

6. De Bièvre P (2006) On 'quality of a measurement result'. Accred Qual Assur 11:597-598

7. BIPM, IEC, IFCC, ILAC, IUPAC, IUPAP, ISO, OIML, The International Vocabulary of metrology - Basic and general concepts and associated terms (VIM), 3rd edition, JCGM 200:2008; it is usually called "VIM 3" http://www.bipm.org/en/publications/ guides/vim.html entry 3.2

8. BIPM, IEC, IFCC, ILAC, IUPAC, IUPAP, ISO, OIML, The International Vocabulary of metrology - Basic and general concepts and associated terms (VIM), 3rd edition, JCGM 200:2008; it is usually called "VIM 3" http://www.bipm.org/en/publications/ guides/vim.html entry 5.12

9. BIPM, IEC, IFCC, ILAC, IUPAC, IUPAP, ISO, OIML, The International Vocabulary of metrology - Basic and general concepts and associated terms (VIM), 3rd edition, JCGM 200:2008; it is usually called "VIM 3" http://www.bipm.org/en/publications/ guides/vim.html entry 2.34

10. BIPM, IEC, IFCC, ILAC, IUPAC, IUPAP, ISO, OIML, The International Vocabulary of metrology - Basic and general concepts and associated terms (VIM), 3rd edition, JCGM 200:2008; it is usually called "VIM 3" http://www.bipm.org/en/publications/ guides/vim.html entry 2.28

11. BIPM, IEC, IFCC, ILAC, IUPAC, IUPAP, ISO, OIML, The International Vocabulary of metrology - Basic and general concepts and associated terms (VIM), 3rd edition, JCGM 200:2008; it is usually called "VIM 3" http://www.bipm.org/en/publications/ guides/vim.html entry 2.29

12. BIPM, IEC, IFCC, ILAC, IUPAC, IUPAP, ISO, OIML, The International Vocabulary of metrology - Basic and general concepts and associated terms (VIM), 3rd edition, JCGM 200:2008; it is usually called "VIM 3" http://www.bipm.org/en/publications/ guides/vim.html entry 2.6

13. De Bièvre P (2007) Fitness for purpose is different from a performance specification. Accred Qual Assur 12:501

14. BIPM, IEC, IFCC, ILAC, IUPAC, IUPAP, ISO, OIML, The International Vocabulary of metrology - Basic and general concepts and associated terms (VIM), 3rd edition, JCGM 200:2008; it is usually called "VIM 3" http://www.bipm.org/en/publications/ guides/vim.html entry 2.3 